\title{
Role of Benzyladenine Seed Priming on Growth and Physiological and Biochemical Response of Soybean Plants Grown under High Salinity Stress Condition
}

\author{
Phetole Mangena $(1)$ \\ Department of Biodiversity, School of Molecular and Life Sciences, Faculty of Science and Agriculture, University of Limpopo, \\ Private Bag X1106, Sovenga 0727, South Africa \\ Correspondence should be addressed to Phetole Mangena; mangena.phetole@gmail.com
}

Received 8 August 2020; Revised 30 August 2020; Accepted 31 August 2020; Published 9 September 2020

Academic Editor: Allen Barker

Copyright (C) 2020 Phetole Mangena. This is an open access article distributed under the Creative Commons Attribution License, which permits unrestricted use, distribution, and reproduction in any medium, provided the original work is properly cited.

Salinity is one of the most important abiotic stresses that affect vegetative growth, reproductive yield, biomass distribution, and physiological parameters of many crop plants. A study was conducted to evaluate these parameters in soybean plants (cv. Peking and LS678), following seed priming with benzyladenine $(2.16 \mu \mathrm{M})$. Soybean plants were subjected to salinity stress imposed by irrigation with a high amount of $\mathrm{NaCl}(250 \mathrm{mM})$ solution under greenhouse conditions. Results showed that exogenously applied benzyladenine dramatically improved growth, biomass, and yield parameters as a priming solution compared to hydroprimed plants exposed to similar salt stress conditions. High reduction in mean photosynthetic pigments $(0.87-1.88)$, carbohydrates (24.942-27.091\%), phenolic content (2.28-2.33), flavonoids (2.37-2.11), and antioxidant capacity (34.5-37.2\%) was observed in plants developed from hydroprimed seeds under salt conditions. These findings suggest that priming of seeds with $2.16 \mu \mathrm{M}$ benzyladenine improved the vegetative, reproductive, and physiological responses of soybeans under induced salinity stress.

\section{Introduction}

The poor agricultural practices such as ineffective irrigation systems and drought stress continue to cause oversalinity in soil used for planting of agroeconomically important legume crops. Salinity stress also known as hyperionization involves osmotic and ionic stress that cause changes to physiological and metabolic processes in plants [1]. This is an ever-increasing problem for agriculture in arid and semiarid regions, as frequently seen in developing countries [2]. Salinity poses a great threat to the natural status of the environment and crop production, particularly in soybean growth and development. Soybean is one of the most important pulse crops and generally considered highly sensitive to salinity stress. This crop contains high amounts of proteins (45\%), oils $(28 \%)$, carbohydrates $(12 \%)$, saturated fatty acids $(12 \%)$, and unsaturated fatty acids (24\%) and serves as a major potential source for biodiesel production [3, 4]. Amirjani [5] reported a reduction in various growth and yield parameters of soybean resulting from the accumulation of $\mathrm{Na}^{+}$and $\mathrm{Cl}^{-}$ ions in plant tissues. This study elaborated on $\mathrm{NaCl}$ effects on growth, mineral composition, proline content, and antioxidant enzyme activity which were dramatically reduced by different levels of salt stress $(10,100$, and $200 \mathrm{mM} \mathrm{NaCl})$. The primary effects of salinity in soybean, such as other legumes, are reduced cell growths, assimilated production, and membrane dysfunctions, as well as decreased cytosolic metabolism leading to production of reactive oxygen species (ROS). Furthermore, Hamayun et al. [6] reported that salinity stress dramatically decreased growth and yield components of soybean cultivar Hwangkeumkong by affecting endogenous levels of secondary metabolite, gibberellic acid (GA), jasmonic acid (JA), salicylic acid (SA), and abscisic acid (ABA). However, Flower and Colmer [7] reported that plant response against salinity differs widely according to species, including at the cultivar level. The application and uptake of plant growth regulators such as cytokinins by plants may lead to increased tolerance of crops to salinity. 
Such exogenously applied plant hormones, for example, naphthalene acetic acid (NAA) and 6-benzyladenine (BA), have been used to improve vegetative growth and yields by foliar applications $[8,9]$. Cytokinins are well known for stimulating or inhibiting growth of plants at many physiological stages such as, germination, and flowering.

Since literature has thoroughly elaborated these impacts on growth and development of soybeans under moderate and severe conditions. No report could be found on the use of BA and the seed priming method to improve the growth of soybean under high salt stress conditions. The objective of this study was, therefore, to evaluate the effects of an optimum amount of BA on the growth, yields, biomass, and physiological parameters of soybean plants subjected to a high level of salinity stress.

\section{Materials and Methods}

2.1. Plant Material, Disinfection, and Osmopriming Treatment. The research was conducted using a hydroponic culture system at Turfloop, University of Limpopo, South Africa, from September 2018 to December 2019. Freshly harvested soybean (Glycine max $(L)$ Merrill) seeds, cultivar Peking, and LS678 were used in this study. The seeds were surface-sterilized for 16 hours using chlorine gas [10] and, then, primed by overnight imbibition in a solution containing deionized water and $2.16 \mu \mathrm{M}$ BA. Soybean seeds soaked in sterile deionized water (hydroprimed) were used as a negative control; meanwhile, a positive control consisted of BA-primed seeds. Priming of seeds was performed in the dark $\left(24 \pm 2^{\circ} \mathrm{C}\right)$, with gentle agitation on a Labcon platform shaker (speed of $175 \mathrm{rpm}$ ) at room temperature. The BA concentration chosen for this experiment was based on the findings from previous studies.

\subsection{Seed Germination, Seedling Growth, and Induced Salinity} Stress. A total of 90 randomly distributed $25 \mathrm{~cm}$ plastic pots were prepared for each cultivar, containing pasteurised mixture of vermiculite and sand at ratio $2: 1$. The vermiculite and sand were specifically used as the support medium because they constitute a nutrient-free medium. Primed soybean seeds were sown and germinated on the mixture; whereby established seedlings were watered daily with halfstrength Hoagland mineral nutrient solution until they reached the V2 stage. To test for the effect of high salt stress, plants were divided into two subsamples for growth and biomass analyses. Salt stress was imposed only on plants used as negative control and treatment plants developed from BA-primed seeds. The positive control plants received only distilled water, while negative control plants and plants developed from BA-primed seeds were watered once a week with $250 \mathrm{mM}$ solution of the salt. The solution was prepared using analytical reagent-grade sodium chloride $(\mathrm{NaCl})$ with a molar weight of $58.44 \mathrm{~g} / \mathrm{mol}$. Various reports including Khan et al. [11] and Rahneshan et al. [12] guided this level of induced salinity, with the highest chosen amount of sodium chloride.
2.3. Biochemical, Morphological, and Physiological Analyses. Leaf samples were randomly harvested at the late V5 stage for the isolation and spectrophotometric determination of photosynthetic pigments according to Sumanta et al. [13]. Quantitative determination of phenolics, as well as flavonoids, using Folin-Ciocalteu assay and antioxidant activity was conducted using 2,2-diphenyl-1-picrylhydrazyl (DPPH) assay by quenching free radicals of the sampled leaves according to Chandra et al. [14], and total carbohydrates were assayed using the Nelson-Somogyi procedure [15]. Evaluation of growth and biomass parameters was performed immediately when blooming or anthesis started at the late V5 stage, while yield analysis was conducted throughout until the late R8 stage. Leaf area (where $L$ is the length and $W$ is the width of the central leaflet of a trifoliate) and biomass fraction (where $B F$ refers to biomass fraction, $F w$ refer to fresh weight, and $D w$ to dry weight of each plant organ) were determined using the equations by Richter et al. [16] and Poorter et al. [17], respectively.

$$
\begin{aligned}
\mathrm{LA} & =2.0185(L \times W), \\
\mathrm{BF} & =\frac{F w-D w}{F w} \times 100 .
\end{aligned}
$$

2.4. Growth Conditions and Statistical Analysis. The experimental design consisted of 45 replicate pot samples used for vegetative growth and biomass analyses and 45 pots for measuring yield parameters. Data collected were analysed using two-way analysis of variance (ANOVA), and significant differences were determined at 5\% confidence level using Duncan's test.

\section{Results and Discussion}

3.1. Effect of $\mathrm{NaCl}$ and $\mathrm{BA}$ on Plant Growth and Yield. Results presented in this study demonstrated the depressive effects of $\mathrm{NaCl}$ and the importance of $\mathrm{BA}$ on growth, biomass, and yield in soybean. Plant growth inhibition was more pronounced in soybeans subjected to salinity stress without hormonal priming. The related salinity stress effects in soybean were reported by Amirjani [5] and also by Hamayun et al. [6] for cultivar Hwangkeumkong. All plants derived from BA-treated seeds were used as a positive control, and treatment exhibited improved plant growths. Morphological variations were observed amongst the plants, particularly in their roots and stomatal density compared to marginal increases observed in shoot lengths, mean branch numbers, and leaf area (Table 1). The plant height of soybeans not subjected to salt stress was significantly higher with 50.3 and $51.6 \mathrm{~cm}$ mean length for Peking and LS678 (Table 1), respectively. These plants produced a mean shoot length slightly higher than BA-primed soybean plants subjected to salt stress (Peking- $37.2 \mathrm{~cm}$ and LS678- 39.6), followed by those treated as negative control with 36.8 and $35.5 \mathrm{~cm}$ for Peking and LS678, respectively.

The observations made above were identical to root lengths and the mean number of branches in both cultivars 
TABLE 1: Mean vegetative response in terms of the shoot length (SL), root length (RL), number of branches (MnB), leaf area (LA), stomatal density (SD), and relative water content of Peking and LS678 soybeans subjected to high salinity stress.

\begin{tabular}{|c|c|c|c|c|c|c|c|}
\hline Cultivar & Treatment & $\mathrm{SL}(\mathrm{cm})$ & $\mathrm{RL}(\mathrm{cm})$ & $\mathrm{MnB}$ & $\mathrm{LA}\left(\mathrm{cm}^{2}\right)$ & $\mathrm{SD}$ & RWC (\%) \\
\hline \multirow{3}{*}{ Peking } & $\mathrm{NaCl}_{\mathrm{A}}$ & $50.3^{\mathrm{b}}$ & $40.6^{\mathrm{a}}$ & $7.2^{\mathrm{a}}$ & $5.51^{\mathrm{a}}$ & $163^{\mathrm{a}}$ & $86.7^{\mathrm{a}}$ \\
\hline & $\mathrm{NaCl}_{\mathrm{B}}$ & $36.8^{\mathrm{d}}$ & $36.2^{\mathrm{b}}$ & $5.9^{\mathrm{cb}}$ & $4.22^{\mathrm{dc}}$ & $102^{\mathrm{d}}$ & $42.9^{\mathrm{f}}$ \\
\hline & $\mathrm{NaCl}_{\mathrm{B}}+\mathrm{BA}$ & $37.2^{\mathrm{d}}$ & $34.1^{\mathrm{c}}$ & $6.3^{\mathrm{b}}$ & $4.69^{\mathrm{b}}$ & $154^{\mathrm{b}}$ & $62.8^{\mathrm{d}}$ \\
\hline \multirow{3}{*}{ LS678 } & $\mathrm{NaCl}_{\mathrm{A}}$ & $51.6^{\mathrm{a}}$ & $40.2^{\mathrm{a}}$ & $7.0^{\mathrm{a}}$ & $5.32^{\mathrm{a}}$ & $159^{\mathrm{a}}$ & $80.2^{\mathrm{b}}$ \\
\hline & $\mathrm{NaCl}_{\mathrm{B}}$ & $35.5^{\mathrm{e}}$ & $33.4^{\mathrm{d}}$ & $5.0^{\mathrm{d}}$ & $4.29^{\mathrm{cb}}$ & $106^{\mathrm{d}}$ & $52.3^{\mathrm{e}}$ \\
\hline & $\mathrm{NaCl}_{\mathrm{B}}+\mathrm{BA}$ & $39.6^{\mathrm{cb}}$ & $30.5^{\mathrm{e}}$ & $6.7^{\mathrm{ab}}$ & $5.21^{\mathrm{a}}$ & $149^{\mathrm{c}}$ & $72.1^{\mathrm{c}}$ \\
\hline
\end{tabular}

Mean values with similar superscript letters within columns are not significantly different at $5 \%$ confidence level according to Duncan's test. NaCl ${ }_{\mathrm{A}}$ is the $0 \mathrm{mM}$, and $\mathrm{NaCl}_{\mathrm{B}}$ refers to $250 \mathrm{mM}$ of sodium chloride used.

TABLe 2: Mean yield responses in terms of flowering (Flw), number of pods/plant (MPP), pod length (PL), pod weight (PW), number of seeds/pod (NSP), and seed yield (SY) of Peking and LS678 soybeans grown under high amount of $\mathrm{NaCl}$.

\begin{tabular}{lccccccc}
\hline Cultivar & Treatment & Flw (\%) & MPP & PL $(\mathrm{cm})$ & PW $(\mathrm{g})$ & NSP & SY $(\mathrm{g} / \mathrm{plant})$ \\
\hline \multirow{3}{*}{ Peking } & $\mathrm{NaCl}_{\mathrm{A}}$ & $98.2^{\mathrm{a}}$ & $38.2^{\mathrm{a}}$ & $3.95^{\mathrm{a}}$ & $1.33^{\mathrm{b}}$ & $3.0^{\mathrm{a}}$ & $20.30^{\mathrm{c}}$ \\
& $\mathrm{NaCl}_{\mathrm{B}}$ & $35.5^{\mathrm{f}}$ & $11.8^{\mathrm{f}}$ & $3.55^{\mathrm{e}}$ & $1.06^{\mathrm{e}}$ & $3.0^{\mathrm{a}}$ & $9.22^{\mathrm{f}}$ \\
& $\mathrm{NACl}_{\mathrm{B}}+\mathrm{BA}$ & $60.7^{\mathrm{d}}$ & $19.4^{\mathrm{d}}$ & $3.87^{\mathrm{b}}$ & $1.44^{\mathrm{a}}$ & $3.0^{\mathrm{a}}$ & $14.16^{\mathrm{d}}$ \\
\multirow{2}{*}{ LS678 } & $\mathrm{NaCl}_{\mathrm{A}}$ & $94.5^{\mathrm{b}}$ & $40.9^{\mathrm{b}}$ & $3.72^{\mathrm{c}}$ & $1.22^{\mathrm{c}}$ & $3.0^{\mathrm{a}}$ & $21.40^{\mathrm{a}}$ \\
& $\mathrm{NaCl}_{\mathrm{B}}$ & $40.1^{\mathrm{e}}$ & $13.4^{\mathrm{e}}$ & $3.62^{\mathrm{d}}$ & $1.11^{\mathrm{d}}$ & $3.0^{\mathrm{a}}$ & $10.75^{\mathrm{e}}$ \\
& $\mathrm{NaCl}_{\mathrm{B}}+\mathrm{BA}$ & $66.3^{\mathrm{c}}$ & $27.2^{\mathrm{c}}$ & $3.99^{\mathrm{a}}$ & $1.32^{\mathrm{b}}$ & $3.0^{\mathrm{a}}$ & $16.38^{\mathrm{b}}$ \\
\hline
\end{tabular}

Mean values with similar superscript letters within columns are not significantly different at $0.05 \%$ confidence level according to Duncan's test. $\mathrm{NaCl}_{\mathrm{A}}$ refers to $0 \mathrm{mM}$, and $\mathrm{NaCl}_{\mathrm{B}}$ to $250 \mathrm{mM}$ of sodium chloride used.

following exposure of soybeans to $250 \mathrm{mM} \mathrm{NaCl}$ (Table 1). The lowest mean branch number (5.0) was recorded in soybean cultivar LS678 developed from hydroprimed seeds along with salt stress. Furthermore, hydroprimed plants showed a significant decrease in the leaf area $\left(4.22-4.29 \mathrm{~cm}^{2}\right)$ due to wilting and senescence, stomatal density (102-6), and percent of relative water content. This was possibly due to dehydration as a result of salt stress than the highest of $5.21 \mathrm{~cm}^{2}$ average leaf area recorded for LS678, 154 stomata density in Peking, and 72.1\% water content recorded in LS678 plants, all established from BAprimed seeds (Table 1). Ozturk et al. [18], Sari and Ceylan [19], and Khan et al. [20] also reported similar findings attributed to high salinity stress. However, observations made in this study clearly indicated that BA improved both the plant morphology and growth of soybeans even under salinity stress. According to ShaoWen et al. [21] the application of BA raised the growth and development of soybean sprouts, including the low yield of $\mathrm{BA}$ residues detected following the soaking method. This report, together with that of Basuchaudhuri [9], emphasised the role of cytokinins, particularly BA on the improvement of plant growth and development.

This study indicated that soybean yield is more decisively determined by flowering and the number of pods produced. The high number of pods observed in the control (+ve) plants and experimental plants resulted into high seed yield recorded for LS678 and Peking (Table 2), respectively. Yashima et al. [22] and Basuchaudhuri [9] elaborating that pod number/flowering among other yield components are key factors for giving high yields also reported this. Lower percentage flowering and pod number recorded for LS678 $(40.1 \%, 13.4)$ and Peking $(35.5 \%, 11.8)$, respectively, resulted into low seed yield in plants exposed to salt stress without hormonal priming (Table 2). In contrast, both cultivars gave improved results of $60.7 \%$ and $66.3 \%$ for flowering, as well as 27.2 and 19.4 mean pods, consecutively, on BA-treated plants exposed to salinity stress. This clearly indicated that high $\mathrm{NaCl}$ stress and BA influenced variation in abscission of reproductive structures of soybeans. Many researchers also indicated the use of BA to reduce these effects, especially flower and young pod abortion [23-25].

3.2. Effect of $\mathrm{NaCl}$ Stress on Biomass and Biochemical and Physiological Response in Soybean. The high salinity level used significantly reduced shoot and root biomass in plants subjected to stress without priming. Maximum reduction of biomass in leaves $(1.3 \mathrm{~g} / \mathrm{g})$ and roots $(2.1 \mathrm{~g} / \mathrm{g})$ was observed in soybean cultivar Peking (Figure 1(b)). This was followed by leaf and root biomass of LS678 at almost the same rate as Peking with $1.6 \mathrm{~g} / \mathrm{g}$ and $2.4 \mathrm{~g} / \mathrm{g}$, respectively (Figure $1(\mathrm{a})$ ). Total biomass allocations in stems were high in both cultivars than total root and leaf biomass fractions (Figures 1(a) and 1(b)). Generally, leaf biomass was more decreased than the total root biomass fractions recorded under the same salinity stress conditions. Salt stress tolerance was observed in plants developed from BA-primed seeds compared to hydroprimed seeds (Figures 1(a) and 1(b)), also with regard to these parameters.

According to Lima et al. [26], stress tolerance is always marked by high biomass production, as growth performance was increased by cytokinin application in this study. The high $\mathrm{NaCl}$ level, furthermore, significantly reduced photosynthetic pigments and carbohydrate levels of highly sensitive hydroprimed soybean plants. However, the reduction in total chlorophyll, carotenoids, and carbohydrates was high in Peking than LS678 (Table 3). These decreases were followed by more reductions in total 

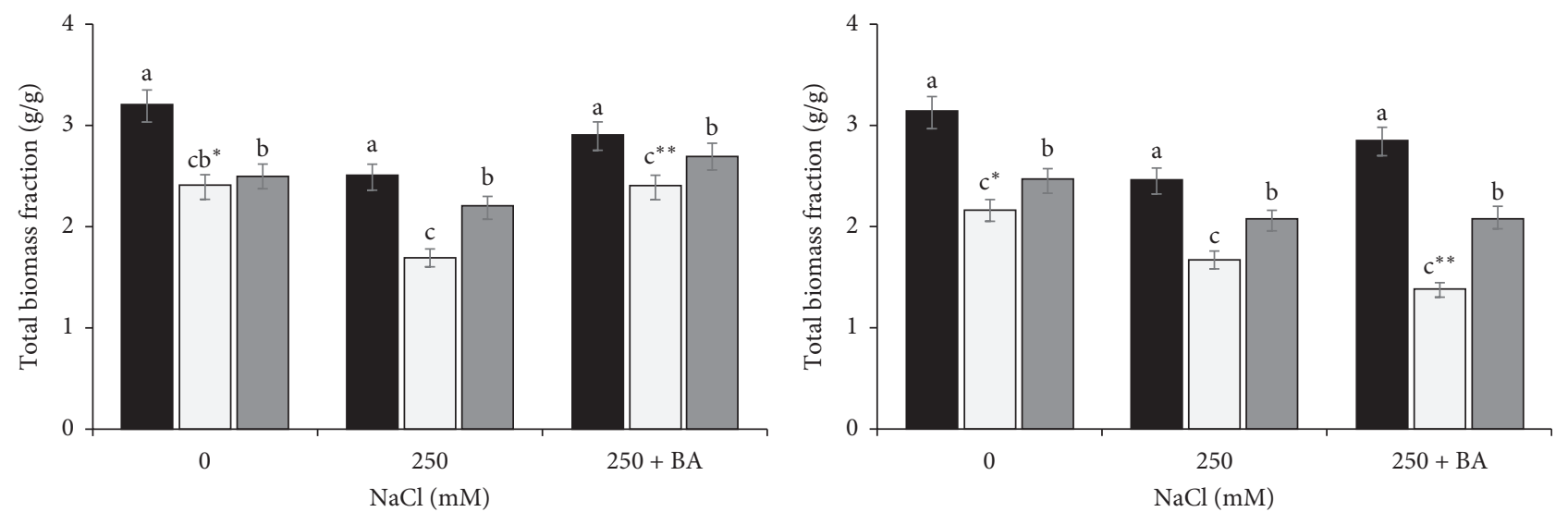

Stems

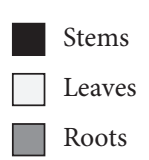

(a)

(b)

Figure 1: Total biomass fractions of $\mathrm{NaCl}$ stressed soybeans cultivar LS678 (a) and Peking (b). Each value represents the mean of three replicates \pm SE.

TABLE 3: Mean biochemical and physiological response of Peking and LS678 soybean plants subjected to salinity stress.

\begin{tabular}{|c|c|c|c|c|c|c|c|}
\hline Cultivar & Treatment & $\begin{array}{l}\text { Phenolics (mg/ } \\
\text { g) } \pm \text { SD }\end{array}$ & $\begin{array}{c}\text { Flavonoids (mg/ } \\
\mathrm{g}) \pm \mathrm{SD}\end{array}$ & $\begin{array}{c}\text { Carbohydrates (mg/ } \\
\text { g) } \pm S D\end{array}$ & $\begin{array}{c}\text { Total chl } \\
(a+b)\end{array}$ & Car & $\begin{array}{c}\text { Antioxidant activity } \\
(\%) \pm S D\end{array}$ \\
\hline \multirow{3}{*}{ Peking } & $\mathrm{NaCl}_{\mathrm{A}}$ & $3.084 \pm 0.481^{\mathrm{b}}$ & $2.630 \pm 0.661^{\mathrm{bc}}$ & $70.380 \pm 0.319^{\mathrm{a}}$ & $2.89^{\mathrm{b}}$ & $1.47^{\mathrm{a}}$ & $44.20 \pm 0.176^{\mathrm{d}}$ \\
\hline & $\mathrm{NaCl}_{\mathrm{B}}$ & $2.339 \pm 0.240^{c}$ & $2.371 \pm 0.345^{\mathrm{b}}$ & $27.091 \pm 0.426^{\mathrm{e}}$ & $1.88^{\mathrm{b}}$ & $0.23^{\mathrm{d}}$ & $34.54 \pm 0.160^{\mathrm{f}}$ \\
\hline & $\mathrm{NaCl}_{\mathrm{B}}+\mathrm{BA}$ & $3.980 \pm 0.324^{\mathrm{a}}$ & $2.961 \pm 0.694^{\mathrm{a}}$ & $38.221 \pm 0.303^{\mathrm{d}}$ & $2.31^{\mathrm{a}}$ & $0.49^{c}$ & $66.17 \pm 0.468^{b}$ \\
\hline \multirow{3}{*}{ LS678 } & $\mathrm{NaCl}_{\mathrm{A}}$ & $3.115 \pm 0.454^{\mathrm{b}}$ & $2.113 \pm 0.870^{c}$ & $60.014 \pm 0.120^{b}$ & $2.99^{\mathrm{a}}$ & $1.02^{\mathrm{b}}$ & $56.01 \pm 0.894^{\mathrm{c}}$ \\
\hline & $\mathrm{NaCl}_{\mathrm{B}}$ & $2.281 \pm 0.394^{c}$ & $1.008 \pm 0.274^{\mathrm{d}}$ & $24.942 \pm 0.745^{\mathrm{f}}$ & $0.87^{\mathrm{b}}$ & $0.24^{\mathrm{d}}$ & $37.27 \pm 0.737^{\mathrm{e}}$ \\
\hline & $\mathrm{NaCl}_{\mathrm{B}}+\mathrm{BA}$ & $4.026 \pm 0.222^{\mathrm{a}}$ & $2.586 \pm 0.466^{\mathrm{cb}}$ & $58.766 \pm 0.097^{\mathrm{c}}$ & $2.13^{\mathrm{a}}$ & $0.52^{c}$ & $73.93 \pm 0.121^{\mathrm{a}}$ \\
\hline
\end{tabular}

Chl- chlorophyll, Car- carotenoids, SD- standard deviation. Mean values within column followed by the same letter are significantly different at $5 \% p$ value according to Duncan's test.

phenolics and flavonoids, in the same order. Results showed that growth and development of soybean plants should be considered as a physiological/biochemical response involving complex and variable metabolic pathways forming different metabolites. Such metabolites, including those quantified are said to decrease under high salt stress $[12,27]$. Although salt stress is a critical factor that severely affects plant growth and metabolism [12], no soybean plants derived from BA-primed seeds exhibited tissue senescence or death of plants. This may be attributed to the cytokinin used, as indicated by Rahneshan [12] emphasizing that application of cytokinins could raise the phytochemicals such as phenolics and flavonoids productivity levels to be higher than those of plants grown under normal growth conditions. The potential high antioxidant capacity in plants developed from BA-primed seeds was attributed to the high amounts of phenolics recorded, particularly in soybean cultivar LS678 (Table 3). This response was observed because phenolics are highly potent antioxidants and free-radical scavengers due to their capacity as strong reducing agents [14]. In general, soybean is reported to be a relatively salt-sensitive crop, and findings by Amirjani [5],
Khan et al. [11], and Rahneshan et al. [12] support the results obtained in this study.

\section{Conclusions}

The present study indicated the critical role of BA on conferring tolerance to induced high salinity stress. Plant growth, yield, biomass, and physiological parameters were significantly improved by seed priming with $2.16 \mu \mathrm{M}$ BA. Therefore, this study validated that plant growth regulators such as cytokinins may be used for various applications to induce abiotic stress tolerance in soybean.

\section{Data Availability}

Data are available from the corresponding author and the institution where the study was conducted at https://ul.ac.za upon request.

\section{Conflicts of Interest}

The author declares that there are no conflicts of interest regarding the publication of this paper. 


\section{Acknowledgments}

The author would like to thank the Department of Biodiversity and Department of Research Administration and Development of the University of Limpopo for their continued support.

\section{References}

[1] B. Gupta and B. Huang, "Mechanism of salinity tolerance in plants: physiological, biochemical, and molecular characterization," International Journal of Genomics, vol. 2014, p. 18, Article ID 701596, 2014.

[2] M. S. Amira and A. Qados, "Effect of salt stress on plant growth and metabolism of bean plant Vicia faba (L.)," Journal of the Saudi Society of Agricultural Sciences, vol. 10, no. 1, pp. 7-15, 2011.

[3] N. Bellaloui, K. N. Reddy, H. A. Bruns et al., "Soybean seed composition and quality: interactions of environment, genotype and management practices," "Soybean seed composition and quality: interactions of environment, genotype and management practices," in Soybeans: Cultivation, Uses and Nutrition, J. E. Maxwell, Ed., pp. 1-48, Nova Science Publishers, New York, NY, USA, 2011.

[4] P. Mangena, "Water stress: morphological and anatomical changes in soybean (Glycine max L.) plants," "Water stress: morphological and anatomical changes in soybean (Glycine max L.) plants," in Plant, Abiotic Stress and Responses to Climate Change, V. Andjelkovic, Ed., Intech Open, London, UK, pp. 9-31, 2018.

[5] M. R. Amirjani, "Effect of salinity stress on growth, mineral composition, proline content, antioxidant enzymes of soybean," American Journal of Plant Physiology, vol. 5, no. 6, pp. 250-360, 2010.

[6] M. Hamayun, S. A. Khan, A. L. Khan et al., "Effect of salt stress on growth attributes and endogenous growth hormones of soybean cultivar Hwangkeumkong," Pakistan Journal of Botany, vol. 42, no. 5, pp. 3103-3112, 2010.

[7] T. J. Flower and T. D. Colmer, "Salinity tolerance in halophytes,” New Phytologist, vol. 179, no. 4, pp. 945-963, 2008.

[8] V. M. Leite, C. A. Rosolem, and J. D. Rodrigues, "Gibberellin and cytokinin effects on soybean growth," Scientia Agricola, vol. 60 , no. 3, pp. 537-541, 2003.

[9] P. Basuchaudhuri, "Influences of plant growth regulators on yield of soybean," Indian Journal of Plant Sciences, vol. 5, no. 4, pp. 25-38, 2016.

[10] P. Mangena, P. William Mokwala, and R. Vassileva Nikolova, "In vitro multiple shoot induction in soybean," International Journal of Agriculture and Biology, vol. 17, no. 4, pp. 838-842, 2015.

[11] M. S. A. Khan, M. A. Karim, M. M. Haque, M. M. Islam, A. J. M. S. Karim, and M. A. K. Mian, "Influence of salt and water stress on growth and yield of soybean genotypes," Pertanika Journal of Tropical Agricultural Science, vol. 39, no. 2, pp. 167-180, 2016.

[12] Z. Rahneshan, F. Nasibi, and A. A. Moghadam, "Effects of salinity stress on some growth, physiological, biochemical parameters and nutrients in two pistachio (Pistacia vera L.) rootstocks," Journal of Plant Interactions, vol. 13, no. 1, pp. 73-82, 2018.

[13] N. Sumanta, C. I. Haque, J. Nishika, and R. Suprakash, "Spectrophotometric analysis of chlorophylls and carotenoids from commonly grown fern species by using various extracting solvents," Research Journal of Chemical Sciences, vol. 4, no. 9, pp. 63-69, 2014.

[14] S. Chandra, S. Khan, B. Avula et al., "Assessment of total phenolic and flavonoid content, antioxidant properties, and yield of aeroponically and conventionally grown leafy vegetables and fruit crops: a comparative study," Evidence-Based Complementary and Alternative Medicine, vol. 2014, Article ID 253875, 9 pages, 2014.

[15] F. E. Prado, J. A. González, C. Boero, and A. R. Sampietro, "A simple and sensitive method for determining reducing sugars in plant tissues. Application to quantify the sugar content in quinoa (Chenopodium quinoa Willd.) seedlings," Phytochemical Analysis, vol. 9, no. 2, pp. 58-63, 1998.

[16] G. L. Richter, A. Z. Junior, N. A. Streck et al., "Estimating leaf area of modern soybean cultivars by non-destructive method," Crop production and Management, vol. 74 , no. 4, pp. 476-425, 2014.

[17] H. Poorter, K. J. Niklas, P. B. Reich, J. Oleksyn, P. Poot, and L. Mommer, "Biomass allocation to leaves, stems and roots: meta-analyses of interspecific variation and environmental control," New Phytologist, vol. 193, no. 1, pp. 30-50, 2014.

[18] A. Ozturk, A. Unlukara, A. Ipek, and B. Gurbuz, "Effects of salt stress and water deficit on plant growth and essential oil content of lemon balm (Melissa officinalis)," Pakistan Journal of Botany, vol. 36, no. 4, pp. 787-792, 2004.

[19] A. O. Sari and A. Ceylan, "Yield characteristics and essential oil composition of lemon balm (Melissa officinalis L.) grown in the Aegean region in Turkey," Tropical Journal of Agriculture and Forest, vol. 26, no. 4, pp. 217-224, 2002.

[20] H. A. Khan, M. A. Pervez, C. M. Ayub et al., "Hormonal priming alleviates salt stress in hot pepper (Capsicum annuum L.)," Soil Environment, vol. 28, pp. 130-135, 2009.

[21] H. ShaoWen, Y. Jie, S. Y. Ming, T. YangWei, Y. Huaijie, and C. L. Hong, "Effects of 6-benzylaminopurine on soybean sprouts growth and determination of its residue," Southern Journal of Agriculture, vol. 46, no. 2, pp. 255-259, 2015.

[22] Y. Yashima, A. Kaihatsu, T. Nakajima, and M. Kokubun, "Effects of source/sink ratio and cytokinin application on pod set in soybean," Plant Production Science, vol. 8, no. 2, pp. 139-144, 2005

[23] L. Nagel, R. Brewster, W. E. Riedell, and R. N. Reese, "Cytokinin regulation of flower and pod set in soybeans (Glycine $\max ($ L.) Merr.)," Annals of Botany, vol. 88, no. 1, pp. 27-31, 2001.

[24] K. Nonokawa, T. Nakajima, T. Nakamura, and M. Kokubun, "Effect of synthetic cytokinin application on pod setting of individual florets within raceme in soybean," Plant Production Science, vol. 15, no. 2, pp. 79-81, 2012.

[25] P. Mangena and P. W. Mokwala, "The influence of seed viability on germination and in vitro multiple shoot regeneration of soybean (Glycine max L.)," Agriculture, vol. 9, no. 35, pp. 1-12, 2019.

[26] M. d. F. Lima, N. B. Eloy, J. A. B. d. Siqueira, D. Inzé, A. S. Hemerly, and P. C. G. Ferreira, "Molecular mechanisms of biomass increase in plants," Biotechnology Research and Innovation, vol. 1, no. 1, pp. 14-25, 2017.

[27] R. Munns, "Comparative physiology of salt and water stress," Plant, Cell and Environment, vol. 25, no. 2, pp. 239-250, 2002. 